\title{
GREEN CONCRETE FOR SUSTAINABLE CONSTRUCTION
}

\author{
Karma Wangchuk ${ }^{1}$, Kelzang Tsheten ${ }^{2}$, Kinga Yezer ${ }^{3}$ Loday $^{4}$ \\ 1,2,3,4 Student (IV/IV), Civil Department, KL University, Andhra Pradesh, India \\ kamongchu@yahoo.com,kel.ten106@outlook.com,yoezerce@gmail.com,lodayster@gmail.com
}

\begin{abstract}
There are many choices in regard to selection of materials in any type of constructions. Due to growing interest in sustainable construction, engineers and architects are motivated to choose the materials which are more sustainable. Green concrete capable for sustainable construction is characterized by application of industrial wastes to reduce consumption of natural resources and energy and pollution of the environment. Replacement of materials over nominal concrete is what makes green concrete more environmental friendly concrete. Marble sludge powder, quarry rocks, crushed concrete and fly ashes are some of the materials used for making green concrete, a sustainable construction.
\end{abstract}

Keywords: Construction Industry, Environmental Impact, Geo-polymer concrete, Green Concrete, Recycled Materials, Sustainable Construction, Virgin Material.

\section{INTRODUCTION}

Color has nothing to do with green concrete. It is a concept of thinking environment into every aspect of the raw materials manufacture over construction, mixture design to structural design, and durability. Green concrete is very often considered to be cheap to produce due to the use of recycled material whereby avoiding the charges for the disposal of waste, less energy consumption and greater durability.

While a normal construction practices are guided by short term economic considerations, sustainable construction is focused on best practices which emphasize on long term affordability, durability and effectiveness. At each stage of the life cycle of the construction, it increases ease and quality of life, while minimizing the negative environmental impacts and increasing the economic sustainability of the construction. Any infrastructure designed and constructed in a sustainable way minimizes the use of resources through the whole life cycle of the construction process in which the green concrete play a vital role in achieving the sustainable construction. Having so much of advantageous has lead to popularity in construction world and one of the emerging technology in sustainable construction. Green concrete is a miracle of present and tool for the future when the natural resources are on the verge of extinction.

\section{WHAT IS SUSTAINABLE CONSTRUCTION?}

Sustainable constructions are those constructions which are concern with the minimizing of environmental impact, while optimizing it economically capability.

\section{GREEN CONCRETE FOR SUSTAINABLE CONSTRUCTION: THE CHALLENGE FOR THE CONSTRUCTION INDUSTRY}

The turnout of the construction industry, in any infrastructure like public and commercial building has a major drawback on our ability to maintain a sustainable economy overall and has a major burden on our environment. Furthermore, it is clear that we cannot have a sustainable construction without bringing changes in the concrete technology as it is a major technology that is used by the construction industry.

This paper will discuss how the green concrete would be able to achieve sustainable construction. Conventional concrete with well known advantages has made huge popularity and is widely used material by the construction industry. Yet this popularity of concrete comes with huge impact on environment as well as making the construction unsustainable [1].

More than 5 billion cubic yards of concrete are produced globally. Such quantity require huge amount of natural resources for the aggregate and cement production

Cement is one of the major components of the concrete and contributes to the urban heat island effect when used in concrete. The production of one ton of cement releases one ton of $\mathrm{CO}_{2}$ into the atmosphere. $\mathrm{CO}_{2}$ is known to be greenhouse gas that contributes to the global warming. 
Normal concrete are usually produce with the poor quality which results in a corrosion of reinforced concrete, alkaliaggregate reaction, sulfate attack etc...

The demolition and disposal of concrete structures, pavements, etc., contributes to the solid waste disposal problem, and concrete constitutes the largest single component.

Lastly, requirement of water is so high that the concrete industry uses over one trillion gallon of water each year globally without including wash water and curing water, which becomes a problem in those region where the fresh water is not easily available.

The above mention points seem to indicate that the concrete industry has become a victim of its own success and therefore is now faced with tremendous challenges but the scenario is not as bad as it might seem, because concrete is inherently an environmentally friendly material, as can be demonstrated readily with study of life-cycle. The challenges, therefore lies in primarily to reduce impact of Portland cement's on the environment. It means, we should use as much as concrete yet with as little Portland cement as possible.

\section{TOOLS AND STRATEGIES}

There are number of strategies whereby green concrete can help in achieving the sustainable construction [2], [3]:

- Increased dependence on recycled materials: Effective use of recycle material can help in reducing the dependence on virgin material.

- Effective use of supplementary cementitious material: Partial replacement of cement can be done by the byproducts of industrial processes, such as fly ash and slag as the production of Portland of cement is responsible for generation of $\mathrm{CO}_{2}$ and huge energy is consumed.

- Improved mechanical properties: Proper use of recycle material can help in improving the mechanical properties.

- Reuse of wash water: The recycling of wash water can be seen practice by the most of the construction industry and required by law in some countries.

- The above mention points clearly indicate that there are means to achieve sustainable construction with the help of green concrete. The means will be discussed in detailed under the following points.

\subsection{Use Geo-Polymer Concrete}

An interesting new innovation in concrete is the use of a variety of Geopolymers. These materials can be combined with materials such as ground granulated slag, fly ash, and natural pozzolanas, to produce concretes without the need to use Portland cement. The materials are said to be strong and durable. Geopolymer has been found to be having high resistance to acid attack. Further concrete exhibits zero alkaliaggregate expansion which is an important property in areas with potentially reactive aggregates. However a major advantage of some types of geopolymer concrete is their greatly improved fire resistance in comparison with traditional Portland cement concretes. Geopolymer concretes produce only about $7 \%$ of the carbon dioxide generated in the production of traditional OPC concretes, giving the material the potential to earn valued carbon credits [4].

\subsection{Partial Replacement of Cement}

The reduction in the use of Portland cement can be achieved with partial replacement of cement by the various cementitious materials, such as fly ash, ground granulated blast furnace slag, metakaoilin, wood ash and limestone powder. The high-strength concrete which was known in the late 1970s is now referred to as high-performance concrete (HPC) because it has been found to be much more than simply strong. Use of this cementitious material has resulted in an improvement of the properties of concrete. These include a lower heat of hydration, which minimizes the risk of thermal contraction cracking, providing the concrete is insulated in order to minimize temperature differentials between the core and surface temperature at early ages. Secondly there is an increased resistance to chemical attack, including that from sulphates and salt water. In addition there is increased resistance and often elimination of alkali - aggregate reaction. There is also increased resistance to chloride induced corrosion of reinforcing steel, which h is especially important in structures, in or adjacent, to the marine environment[4].

\subsubsection{Fly-ash}

The use of fly ash has a number of advantages. It is theoretically possible to replace $100 \%$ of Portland cement by fly ash, but replacement levels above $80 \%$ generally require a chemical activator. Moreover, fly ash can improve certain properties of concrete, such as strength. Since it generates less heat of hydration, it is particularly well suited for mass concrete applications. Fly ash is also widely available, namely wherever coal is being burned. Another advantage is the fact that fly ash is still less expensive than Portland cement. Maybe most important, as a byproduct of coal combustion fly ash would be a waste product to be disposed of at great cost, if we don't make good use of it. By utilizing its cementitious properties of fly ash, we are making best use of its value [1], [2], [3], [4].

\subsubsection{Ground Granulated Blast-Furnace Slag}

Ground granulated blast furnace slag (GGBFS) is another excellent cementitious material. It is obtained by quenching molten iron slag (a by-product of iron and steel making) from a blast furnace in water or steam, to produce a glassy, granular 
product that is then dried and grounded into a fine powder. Here the optimum cement replacement level is somewhere between 70 and $80 \%$. Like fly ash, also GGBFS can improve many mechanical and durability properties of concrete and it generates less heat of hydration. The use of granulated blast furnace slag in concrete has increased considerably in recent years, and this trend is expected to continue. The worldwide production of granulated blast-furnace slag, however, is only about 25 million tones per year. Yet, slag is not as widely available as fly ash. Generally, the comparison of ground granulated blast furnace slag (GGBFS) with Portland cement concrete can be summarized as follows[4]:

- Concrete with Type IS cement (Pozzolana cement) or with higher dosages of GGBFS added at the mixer usually will have lower heat of hydration.

- Concretes containing slag may show somewhat longer time of setting than straight Portland cement mixtures, particularly for moderate and higher dosages and at lower ambient temperatures.

- Concrete with Type IS cement gains strength more slowly, tending to have lower strength at early ages and equal or higher strength at later ages.

- Increasing slag dosage is associated with lower permeability in concrete.

- Concrete containing GGBFS dosages greater than $35 \%$ by mass of cementitious material, have demonstrated an improvement in the resistance to sulfate attack, as well as suppression of alkali-aggregate expansion.

\subsubsection{Silica Fume (SF)}

Silica fume, also known as microsilica, is an amorphous (noncrystalline) polymorph of silicon dioxide, silica. It is an ultra fine powder collected as a by-product of the silicon and ferrosilicon alloy production and consists of spherical particles with an average particle diameter of $150 \mathrm{~nm}$. This finely divided, glassy powder results from the condensation of silicon oxide gas. Silica fume is composed primarily of silicon dioxide $(\mathrm{SiO} 2)$.Particles are about 100 times smaller than the typical particles of Portland cement. Silica fume is typically used in quantities ranging from 7 to $12 \%$ of the mass of the cementitious material. Perhaps the most important use of this material is as a mineral admixture in concrete. Because of its fine particles, large surface area, and the high $\mathrm{SiO}_{2}$ content, silica fume is a very reactive pozzolan when used in concrete. Worldwide production is estimated to be about 2 million tones. It is generally specified for specialized applications, such as structures exposed to aggressive chemicals. Its primary use is to enhance the durability of concrete by making it less permeable. Silica fume addition benefits concrete in two ways. First, the minute particles physically decrease the void space in the cement matrix this phenomenon is known as packing. Silica fume is added to concrete to increase compressive strength or to improve durability. Properly proportioned silica fume concrete can achieve very high early and ultimate compressive strengths. High-strength concrete is a very economical material for carrying vertical loads in highrise structures. Until a few years ago, 41.36 mpa concrete was considered to be high strength. Today, using silica fume, concrete with compressive strength in excess of $103.42 \mathrm{mpa}$ can be readily produced [4].

\subsubsection{Rice Husk Ash (RHA)}

Rice milling generates a byproduct know as husk. This surrounds the paddy grain. During milling of paddy about 78 $\%$ of weight is received as rice, broken rice and bran .Rest 22 $\%$ of the weight of paddy is received as husk. This husk is used as fuel in the rice mills to generate steam for the parboiling process. This husk contains about $75 \%$ organic volatile matter and the balance $25 \%$ of the weight of this husk is converted into ash during the firing process, is known as rice husk ash (RHA). This RHA in turn contains around $85 \%$ - $90 \%$ amorphous silica. Rice husk ash is not yet commercially available. Along with fly ash and granulated blast furnace slag, rice husk ash, when it becomes commercially available, will be the most significant supplementary cementitious material for use as a partial replacement for Portland cement in concrete to reduce $\mathrm{CO} 2$ emissions. Rice covers $1 \%$ of the earth's surface and is a primary source of food for billions of people. Globally, approximately 600 million tones of rice paddy are produced each year. On average $20 \%$ of the rice paddy is husk, giving an annual total production of 120 million tones [4].

\subsubsection{Silpozz}

Silpoz is made out of RHA which is finer than cement and having a particle size of 25 microns. Finer size of particles helps in filling up the interstices between the cement and the aggregate i.e where the strength and density comes from. And that is why it can reduce the amount of cement in the concrete mix [4]. It has been found that use of silpozz in concrete can increase the compressive strength by $10 \%-20 \%$ and high resistance towards the chemical attack, abrasion and reinforcement corrosion. Further silpozz has a huge potential to be used as replacement of silica fumes at cheaper cost without affecting the quality. In addition to that use of silpozz helps in reducing the heat of hydration as much as by $30 \%$ which helps in preventing the cracks during the casting and also it reduces the water penetration by $60 \%$ proving to be excellent water resistance [5].

\subsection{Use of Recycled Material}

\subsubsection{Concrete Debris}

Apparently concrete debris is the most important successor for reuse as aggregate in new concrete. On the one hand, vast amounts of material are needed for aggregate. On the other hand, construction debris often constitutes the largest single component of solid waste, and probably the largest fraction of this is concrete. Using such debris to produce new concrete 
conserves natural resources, reduces valuable landfill capacity and reducing the use of virgin material.

\subsubsection{Post -Consumer Glass}

Post-consumer glass is another example of a suitable aggregate for concrete. The introduction of post-consumer recycled glass (including coloured glass), substantially reduces consumer landfill waste and increases eligibility for LEED Recycled Material credits. Glass is a unique inert material that could be recycled many times without changing its chemical properties. A major concern regarding the use of glass in concrete is the chemical reaction that takes place between the silica-rich glass particles and the alkali in the pore solution of concrete, i.e., alkali-silica reaction (ASR). This reaction can be very detrimental to the stability of concrete, unless appropriate precautions are taken to minimize its effects. Such preventative actions could be achieved by incorporating a suitable pozzolonic material such as fly ash, silica fume, or ground blast furnace slag in the concrete mix at appropriate proportions.[6]. Ahmad SHAYAN [6] has conducted study on the efficiency of glass powder with the help of concrete expansion tests. A very reactive aggregate was employed in the concrete prism test conducted according to the RTA T364 test method (similar to ASTM C1293). Deleterious expansions are considered to be above $0.03 \%$ or $0.04 \%$ in one year. From the test result it is indicated that even $40 \%$ fine glass powder, which has the potential to release more alkali than $30 \%$ fine glass powder, has effectively suppressed the enormous expansion of the very reactive aggregate in the concrete $(80 \%$ reduction). For less reactive aggregates, the expansion would have been completely suppressed. This confirms the beneficial effects of fine in improving the durability properties of concrete.

\subsubsection{Foundry Sand}

Foundry sand is commonly known as metal casting sand which is having high quality silica sand with uniform physical characteristics. Foundry sand is a byproduct of metal casting industry either ferrous or non ferrous, where sand has been used as a molding material for centuries because of its unique engineering properties. In modern foundry practice, sand is typically recycled and reused through many production cycles. Industry estimates are that approximately 100 million tons of sand are used in production annually. Of that, four (4) to seven (7) million tons are discarded annually and are available to be recycled into other products and industries..Sand used at foundries is of a high quality. Stringent physical and chemical properties must be met as poor quality sand can result in casting defects. Foundries and sand producers invest significant resources in quality control of their sand systems, with extensive testing done to maintain consistency. As a result, FS from an individual facility will generally be very consistent in composition, which is an advantage for most end user applications [7]. Naik, Tharaniyil, and Wendorf [8] has done a study on the performance of foundry by-products in concrete and masonry products, where coarse aggregate was replaced by air-cooled foundry slag (50 and 100\%) and fine aggregate for masonry blocks and paving stones was replaced by foundry sand (up to 35\%). The test result marked that the compressive strength of the concrete with air-cooled foundry slag as its coarse aggregate decreased slightly. On the other hand masonry blocks made with used foundry sand full filled the ASTM requirements for compressive strength, absorption, and bulk density.

\subsubsection{Cupolas Slag}

Slag is by-products by metallurgical processes. The most famous slag are blast furnace slag and steel slag. Their treatment and using are known and their using is very extensive [9]. Cupola slag has also been used as coarse aggregate in concrete. The density $(1280 \mathrm{~kg} / \mathrm{m} 3[80 \mathrm{lb} / \mathrm{ft} 3])$ of cupola slag is between that of normal weight aggregate $(1600$ $\mathrm{kg} / \mathrm{m} 3[100 \mathrm{lb} / \mathrm{ft} 3])$ and structural lightweight aggregate $(1120$ $\mathrm{kg} / \mathrm{m} 3$ [70 lb/ft3]) [10].

\subsubsection{Wood Ash}

Wood ash is the residue powder left after the combustion of wood, such as burning wood in a home fireplace or an industrial power plant. It is used traditionally by gardeners as a good source of potash for domestic gardens. Wood ash can now be used in one of the recycling materials in green concrete. Wood waste is burned with supplementary fuels such as coal, petroleum coke, oil, and gas. Wood ash is composed of both inorganic and organic compounds. The physical and chemical properties of wood ash, which determine its beneficial uses, are influenced by the species of the wood and the combustion methods, which include combustion temperature, efficiency of the boiler, and supplementary fuels used [10]. Naik and Kraus [11] has conducted a study on a wood ash which has huge capability for use as a pozzolanic mineral admixture and an activator in cement-based materials. They use wood ash in the making of concrete with up to $35 \%$ replacement of cementitious materials with wood ash. Test result indicated compressive strengths of $35 \mathrm{MPa}$ (5 ksi), which is appropriate for many structural applications.

\section{CONCLUSIONS}

One must not forget to achieve the sustainable construction. There are various means to achieve sustainable construction and one of the means is through green concrete. Green concrete technology is one of the major steps that a construction industry can implement to achieve sustainable construction with various means as discussed above. With Green concrete Technology we can save the natural materials for future use or the generations to come and sustain it for good amount of time. With the time, the virgin material will deplete and so the cost for the material will increase which 
will add to more cost for the construction but if we use waste materials for construction the virgin materials will become a sustainable material and as well the cost will be reduced. With waste material as alternative we can help reduce the environmental problems and protect the naturally available materials for future generations as well. Our paper basically deals with the tools and strategies to ensure that green concrete can be used in place of Portland cement. The usage of green concrete ensures sustainable development and it's gaining its popularity ever since its inception.

\section{REFERENCES}

[1]. C. Meyer," Concrete as a Green Building Material", Columbia University, New York.pp. 2-3

[2]. Micheal Berry et al, "Changing the Environment: An Alternative "Green" Concrete Produced without Portland Cement", World of Coal Ash Conference , May 4-7 2009, pp. 2-6.

[3]. Christopher Stanley," The Green Concrete Revolution", 35th Conference on Our World in Concrete \& Structure: Singapore, 25 - 27 August 2010.

[4]. Zasiah Tafheem, Shovona Khusru and Sabreena Nasrin, "Environmental Impact of Green Concrete in Practice", International Conference on Mechanical Engineering and Renewable Energy, 22- 24 December 2011. pp. 3.2-3.4.

[5]. rice husk ash. Weblog [Online]. Available from http://www.ricehuskash.com/details.htm. [Accessed 08/08/13]. [6]. Ahmad SHAYAN, 'Value-added Utilisation of Waste Glass in Concrete", IABSE Symposium Melbourne, 2002. pp. 1-10

[7]. Introduction to Foundry Sand ,AFS.Weblog[Online]. Available from:

http://www.afsinc.org/content.cfm?ItemNumber=7075

[Accessed 08/08/13].

[8]. Naik, T. R.; Singh, S. S.; Tharaniyil, M. P.; and Wendorf, R. B.,"Application of Foundry By-Product Materials in Manufacture of Concrete and Masonry Products," ACI Materials Journal, V. 93, No. 1, Jan.-Feb. 1996, pp. 41-50.

[9]. S: P. DEMETER, D. BARICOVA, A. PRIBULOVA " EXPERIENCES WITH CUPOLA SLAG USING BY CONCRETE PRODUCTION", 9th International Multidisciplinary Scientific GeoConference June 14-19, 2009, Vol. 2, 683-688 pp

[10]. Tarun R. Naik, "Green Concrete Using Recycled Material", Concrete International, July 2002, pp.45-49]

[11]. Naik, T. R., and Kraus, R. N., "Wood Ash: A New Source of Pozzolanic Material," Submitted to Concrete International, Oct.

2001, 23 pp

\section{BIOGRAPHIES}

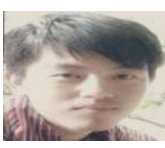

I am Karma Wangchuk, currently pursuing B. Tech (IV/IV) Civil in KL University and specializing in structural engineering

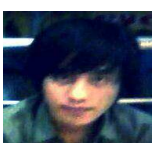

I am Kelzang Tsheten, currently pursuing B. Tech (IV/IV) Civil in KL University and specializing in structural engineering

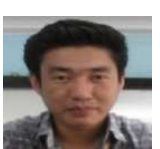

I am Kinga Yezer, currently pursuing B. Tech (IV/IV) Civil in KL University and specializing in structural engineering

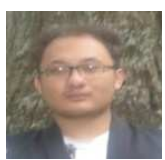

I am Loday, currently pursuing B. Tech (IV/IV) Civil in KL University and specializing in structural engineering 